\title{
Studying Innovation Model Using Structural Equation Modeling and Artificial Neural Network in the Educational System with an Emphasis on Islamic Humanities
}

\author{
Ali Sorayaei ${ }^{1} \&$ Morteza Valiollahpur $^{2}$ \\ ${ }^{1}$ Faculty Member, Department of Management, Islamic Azad University of Babol Branch, Babol, Iran \\ ${ }^{2}$ Ph.D. Student of Education Management, Islamic Azad University of Babol Branch, Babol, Iran \\ Correspondence: Morteza Valiollahpur, Islamic Azad University of Babol Branch, Babol, Iran. E-mail: \\ valiollahpur@yahoo.com
}

Received: March 21, 2016 Accepted: July 1, 2016 Online Published: July 31, 2016

doi:10.5539/jpl.v9n6p87

URL: http://dx.doi.org/10.5539/jpl.v9n6p87

\begin{abstract}
The Holy Quran is a book of the god and creative of the universe and training all beings including humans, express human life needs for grow, progress and evolve. Idea with Islamic thought and attitude is vital in Islamic societies today. Necessary, researches especially in the humanities with creativity and innovation. Educational system is case study in this research. Researcher, study factors affecting on development of innovative with Islamic thought in universities. Data collect tool a questionnaire consisting of 37 questions. Statistical population form city of Babol higher education institutions. The sample size is a total of 419. The model has been confirmed in both classical statistics and artificial intelligence. The Fisher test for equality of structural equation modeling correlation coefficient and artificial neural network indicates the network model greater power. Conclusion, model can be explained in all aspects the sacred system Islamic Republic of Iran with Islamic thought.
\end{abstract}

Keywords: creative, Holy Quran, Islamic human sciences, Islamic Republic of Iran, model of innovation development, land preparation

\section{Introduction}

Education in an era which it is known as the postmodern is a global view and it is understandable for those teachers (instructors, professors, education stakeholders, etc.) and learners (students, pupils, etc.) who want to observe the order formed by the complexity and chaos of their lives. Michael Crichton states that we are not able to understand the sudden and irrational racial variations in the universe structure. However, there are changes (Valiollahpur, 2014). The education system has had a crucial role in the development of human knowledge boundaries through specialized training of people, managers and community leaders and through the development of skills, ingenuity, and intellectual potential of human. It also helps solving different challenges of communities and modifying their imperfections through the reinforcement of exploration and innovation, creativity and invention and the development of a critical spirit among educated people. In this regard, higher education in all countries more or less follows basic and general objectives including fundamental, applied, and scientific research to advance and spread knowledge in the society, training and providing skilled, expert, and efficient human resources required for different sections of society, facilitating the realization of political, economic, social, and cultural goals and improving the cultural level of the society. In the globalization era, the revolution of information and knowledge production, varying, complex, and powerful forces of change has surrounded universities. Therefore, it can be said that change and innovation for higher education and universities is now a necessity rather than an opportunity (Sajadian, 2012). Researchers know that innovation is essential for prosperity and sustainable health of each community because it is a criterion for differentiation of communities and competition between them. Fumio Kodama, a Japanese researcher, says: "Increasing productivity and innovation in a society determines the economic health in all communities of the world." Investment on innovation is needed for effective use of resources, increasing productivity, expanding international trade and promoting the personal and social well-being or living standards, in other words. Countries of the world are to increase their efficiency and to improve their economic status with an emphasis on innovation and one of the main reasons of such emphasis is increasing competition between communities 
(Saeida Ardakani et al., 2012). Having natural talent and creativity is an important foundation for having a creative community. Creativity enrichment will be facilitated through a changing and evolved culture and tradition, the establishment of educational institutions in order to increase human resource capitals and to flourish its quality, and paying attention to the society values which lead to progress and innovation of human resources (Pourtahmasebi et al., 2010). According to the needs and requirements of the Constitution ideals, population growth, international development, new environment of international economy, scientific approaches and new technologies, especially information technology and socio-economic growth needs of the country in the present stage of development, investment, production, and employment as well as the establishment of long-term economic, dynamic, progressive and knowledge-based empowerment require a logical approach towards progressive development and depicting a long-term vision (guidelines for formulating planning studies). And this ideal is achieved only when all aspects including innovative aspects in different branches of science are explained based on the Holy Quran.

In this study, the innovation model of Islamic Humanities is explained and the relationship between the explained factors is analyzed by a case study of education system. According to the literature, the conceptual model and results of investigating the model aspects are presented. Nevertheless, this paper seeks to answer the following question:

Given the planning evolution of the Islamic Republic of Iran, how can be innovation development explained by Islamic attitude and thought?

\section{Concepts, Evidence}

With regard to notification of general science and technology policies of the Islamic Republic of Iran by the supreme leader including science production and innovation development and theorizing, promoting the country's global position in science and technology, development of basic science and fundamental research, we should strive for increasing productivity and optimal use of existing resources in the country and further develop the prosperity and scientific, economic, political and social power of the country. In order to maintain its dynamics, the country requires the development and strategic planning, process improvement and continuous quantitative and qualitative methods and control. Performing and fulfill each of these processes with careful planning will be possible via real, accurate, relevant and up to date information. Iran's Supreme Leader says: "We need research and innovation in the field of humanities. Basic concepts and materials upon which the law, economics, politics and other essential parts of the human sciences can be formed, produced, and processed, are deeply rooted in our Islamic culture and we should use them. Research should necessarily be creative and innovative, especially in the field of human sciences (Valiollahpur, 2015). The Holy Quran, a book revealed by the Lord of the universe and the creator and developer of all beings, including humans, represents human needs for growth, development and evolution. The verses of this book were revealed to the Prophet Mohammad who formed a government and ran it for 10 years and instructions of this book guided him in all moments of difficulty (Gheraati, 2012). One of the attributes of God is considered to be "creative" in Surah Yasin, verse 86 and verse 81 of the Surah Al Hijr, verse86. God is the world's first innovator and creator and his creativity has established great diversity and beauty in the world. Human being as the God's most complete and greatest creature and choices the only creature with thinking abilities among all the world's creatures, In today's world thanks to the power of creativity and innovation, the culture and civilization, science and technology and industry can

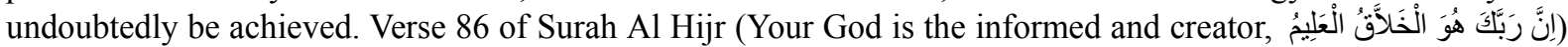
refers to an educational order, which is related to the difference between thought and talent (Al Hijr, verse 86). God knows that all people are not the same. He knows about their internal secrets, intellectual growth, and

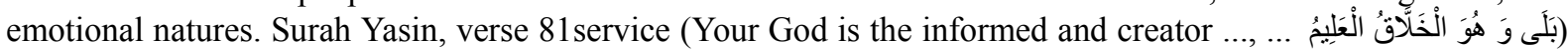
focuses on two great attributes of God: infinite creativity and knowledge and in fact that is a reason of the previous speech that if you doubt on his power of creation, He is creative and if collecting these particles needs knowledge, He is informed and aware of every aspect of the world (Surah Yasin, Verse 81). According to Diani Dardashti (2010), Holy Quran as the eternal miracle of the Prophet (pbuh), with advent in the community of ignorance, guided the people of that era from the darkness of ignorance and light of knowledge. And today, after centuries and after research in various disciplines, foundations of different fields such as sociology, economics, politics, medicine and astronomy have been found in the Quran. And this great book invited people to thinking and creativity and therefore to the purpose of creation, i.e. perfection, by showing the signs and symptoms. In various parts of the Noble Quran, the phrase "Do not you think" or the like can be seen. Qureshi says: The origin of creativity is creation and creation means to measure and appreciate. Since the creation is along with measurement, "Khalq" is defined as creation. Ragheb says: "Khalq" means proper measurement and is used to measure the right thing and to create something from something else. The result of innovation is creativity. 
Innovation is manifested creativity and it is the practical phase of creativity. The use of new ideas, concepts and thought stems from creativity. In fact, innovation is a process that turns the new concept or new idea generated into creativity. According to verse 86 of Surah Al Hijr and verse 81 of Surah Yasin in which the term "creative" is along with "informed", we can conclude that science takes precedence over creativity. The precedence of the word creative over informed shows the greatness of creativity and innovation and shows that innovation is based on science and knowledge and science and knowledge play a major role in the development of creativity. To achieve knowledge, thought is required. In fact, the main source of creativity is science and knowledge which in turn is based on thought. In other words, creativity is one of the main aspects of thinking. Sabzevari refers to the logic definition of "thought": It is the idea is to move towards clear principles and premises and then move from those toward exploring the purpose. In other words, thought is the analysis of man's background information to achieve new information (Valiollahpur, 2015).

\section{Background of the Study}

The creative process is any thinking process to solve problems usefully, innovatively, and scientifically. According to George Seidel, "the ability to relate and connect the threads, regardless of the field or fields, is the bases for creative use of mind". Eric Firm also believes that creativity is the ability to see (being informed) and to answer. Kaiser defines creativity as follows (which is a comprehensive definition): Creativity is the ability to use the mind to create a new ideas or concepts. With regard to these definitions, it is assumed that creativity is to be expected in any activity and is not limited to a particular type of activity (Rezaeian, 2011). In this study, Tong's conceptual model (1998-1999) is an appropriate model to evaluate the factors affecting the development of innovation. In his article, he introduced engagement, leadership, communication, integration, organizational support, knowledge and increasing levels of project and conducting organizational projects as factors affecting the development of innovation. The model is a network and the account of the structural equation model in terms of leadership, organizational support, function, behavior and interaction, coordination and integration, knowledge and skills, information and communication, increasing levels of project and conducting organizational projects (organizational project) are depicted as follows:

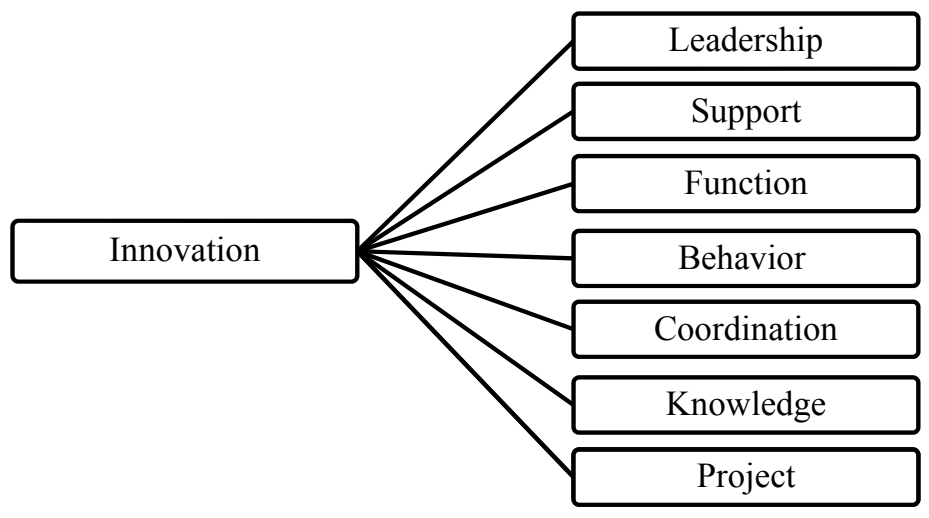

Figure 1. Tang's conceptual model (1998)

Undoubtedly, the development of innovation in Islam-oriented society should be based on Islamic thought and attitude (Islamic spirituality). Thinking which will determine the causes of blessing in society. The aspects of Islamic spirituality can be examined from different perspectives with regard to the Holy Quran, Hadith and multiple narratives and supreme leader speeches. Dr. Ali Panahi have carried out his $\mathrm{PhD}$ thesis under the supervision of university experts and has considered spirituality as change of belief in God into faith in God, according to the Quran and various sayings and Hadithsin religious books of Islam and Shia as well as Imam Khomeini speeches on the definition of faith whose spiritual status and degree is above belief. Considering that spirituality is a component of religious approach, the researcher in this study has chosen faith in God. Changing the belief into religious knowledge, with respect to fact that the faith and knowledge are basic pillars of Islamic spirituality and religious approach to spirituality, the researcher chose religious knowledge in this article. A change of leadership into an insightful leadership, with regard to the importance of insight in religious and political literature insight of Iran and its position in the Supreme Leader speeches, researcher has chosen 
insightful leadership (Roodsaz et al., 2013).

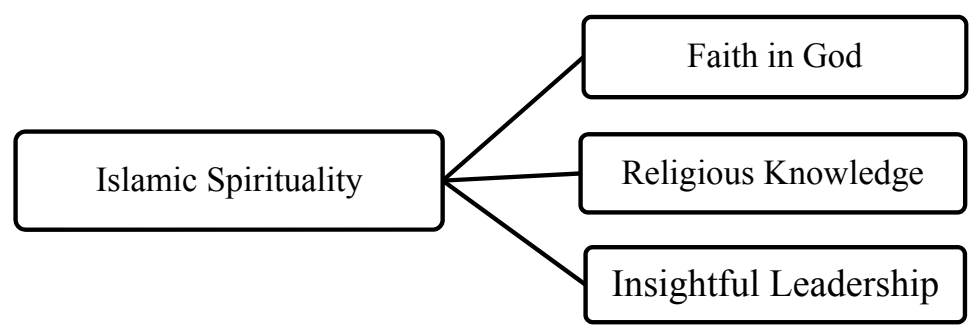

Figure 2. Thought and attitude model (spirituality)

Both of the above models include decisive factors at the individual, group and organizational levels. With regard to organizational level and with regard to the fact that the present study explores the organizational level, conceptual model is depicted as follows;

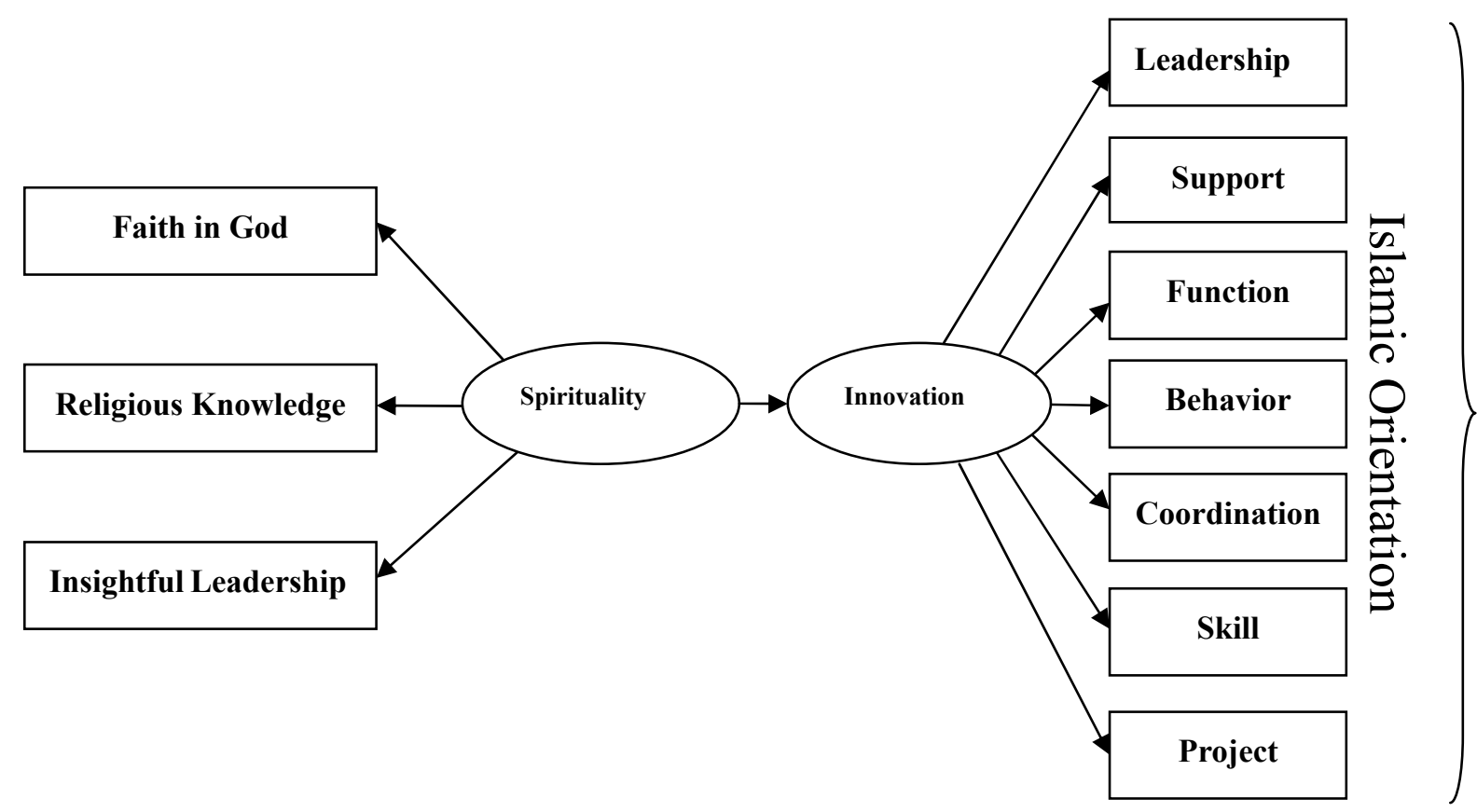

Figure 3. Research conceptual model

\section{Research Questions}

The study seeks to answer the following questions:

1) A good model of innovative thinking is influenced by what criteria and variables?

2) Whether such model can be employed for any organization or system (education, business, industry, etc.)?

3) Given the planning evolution of the Islamic Republic of Iran, how can be innovation development explained by Islamic attitude and thought?

\section{Research Objectives}

The study seeks to fulfill the following objectives:

- Providing a good innovation model with Islamic thought.

- Explaining the innovation model of with Islamic thought and attitude in accordance with the orders of the Supreme Leader. 


\section{Research Method, Population and Sample}

Higher education was investigated in this research. The researcher was interested to study the factors affecting the development of innovation with an Islamic thought in an academic context. The research made use of a descriptive survey method for collecting the data. To validate the test instruments, the content of the questionnaire was developed based on the theoretical framework and to assess the reliability of the study Cronbach's alpha coefficient was calculated using SPSS software. Cronbach's alpha coefficient was equal to $71.4 \%$. In order to conduct the study, in addition to study the available theories and frameworks affecting the development of innovation, the researcher conducted a survey on the students in higher education institutes in Babol through using the questionnaires. In this study, the field study procedure was used to collect the required data. The data collection instrument included an anonymous questionnaire which was used to evaluate the research questions. The researcher-made questionnaire contained 37 questions based on the five-point Likert scale which consisted of very high, high, medium, low and very low.

The population of the study included a number of desired elements having at least one specific trait (Azar et al., 2011). A specific trait refers to a trait that is shared among all elements of the population and distinguishes the population from other populations (Danaiee fard, et al., 2008). Sampling is the process of selection of a limited number of population samples (Uma'Sekaran, 2011). The population of the study consisted of students, professors and staff working in the state, non-profit, Payam Noor and Azad universities in Babol, which conform to the religion of Islam. Given that the population is large, a certain number of participants should be selected from the population as the sample, and by studying this limited sample, features, characteristics and attributes are generalized to the population under the study. The sample was selected randomly (convenient sampling) in this study. A total of 419 participants were selected as the sample of the study.

\subsection{Statistical Data, Data Analysis Method}

According to Steyn et al. (2011), statistics is a tool to collect, calculate and display a set of data, which are classified according to predetermined features. The predetermined features show inclination toward the used instruments and affect the data, those that depend on the subjective decision-making process prior to being selected. Statistics may be useful, however it needs to be confirmed that is not the expected purpose. The purpose is merely within a framework which has been made subjectively and informs us of what we have to say and what we desire to hear. Statistics is the process of data selection. In other words, it reports the effective data and interprets and presents it. Finally, the statistical results can be used to justify the appropriateness of any situation (Valiollahpur, 2014).

This study aims to evaluate the appropriate model forthe development of innovation usingan Islamic thought. In this study, descriptive statistics was used to provide the features and characteristics of the population under the study and inferential statistics was used to analyze and explain the findings of the study. The data obtained from the descriptive statistics was calculated using SPSS software. Moreover, the LISREL software version 8.8 was utilized in order to evaluate the model. A number of softwares like Neuro Solotion, Neural Works Professional can be easily used in order to fit the model through the artificial neural network. In the present paper, the network architecture has been only designed through using the multi-layer perceptron structure and detailed information of artificial intelligence is beyond the scope of this research.

\section{Research Findings}

\section{Descriptive statistics}

Descriptive statistics refers to the calculation of statistical values and indicators through taking into account all its elements (Azar et al., 2011).

Table 1. Descriptive statistics

\begin{tabular}{|c|c|c|c|c|c|c|c|c|}
\hline \multicolumn{3}{|c|}{ Gender } & \multicolumn{3}{|c|}{ Age } & \multicolumn{3}{|c|}{ Education } \\
\hline & Frequency & Percent & & Frequency & Percent & & Frequency & Percent \\
\hline Male & 181 & 43.6 & Under 25 years & 285 & 68.7 & BA & 340 & 81.9 \\
\hline Female & 234 & 56.4 & Over 25 years & 130 & 31.3 & Higher of BA & 75 & 18.1 \\
\hline Total & 415 & 100 & Total & 415 & 100 & Total & 415 & 100 \\
\hline
\end{tabular}


The analysis of the results based on the gender showed that $43.6 \%$ of the respondents were male and $56.4 \%$ of the respondents were female. The results also showed that $68.7 \%$ of the sample was under the age of 25 and $31.3 \%$ were over 25 years of age. Moreover, $81.9 \%$ of the sample was at the undergraduate level and $18.1 \%$ of the sample was at a level above the undergraduate.

Inferential statistics

\section{Fitness of the model through structural equation modeling}

Before examining the model, the normality of the data was determined using the Kolmogorov - Smirnov test. The conceptual model developed in this study is a modified and diminished version of the functional models of innovation development using Islamic thinking and attitudes which is drawn as follows based on the intended sample through using LISREL software.

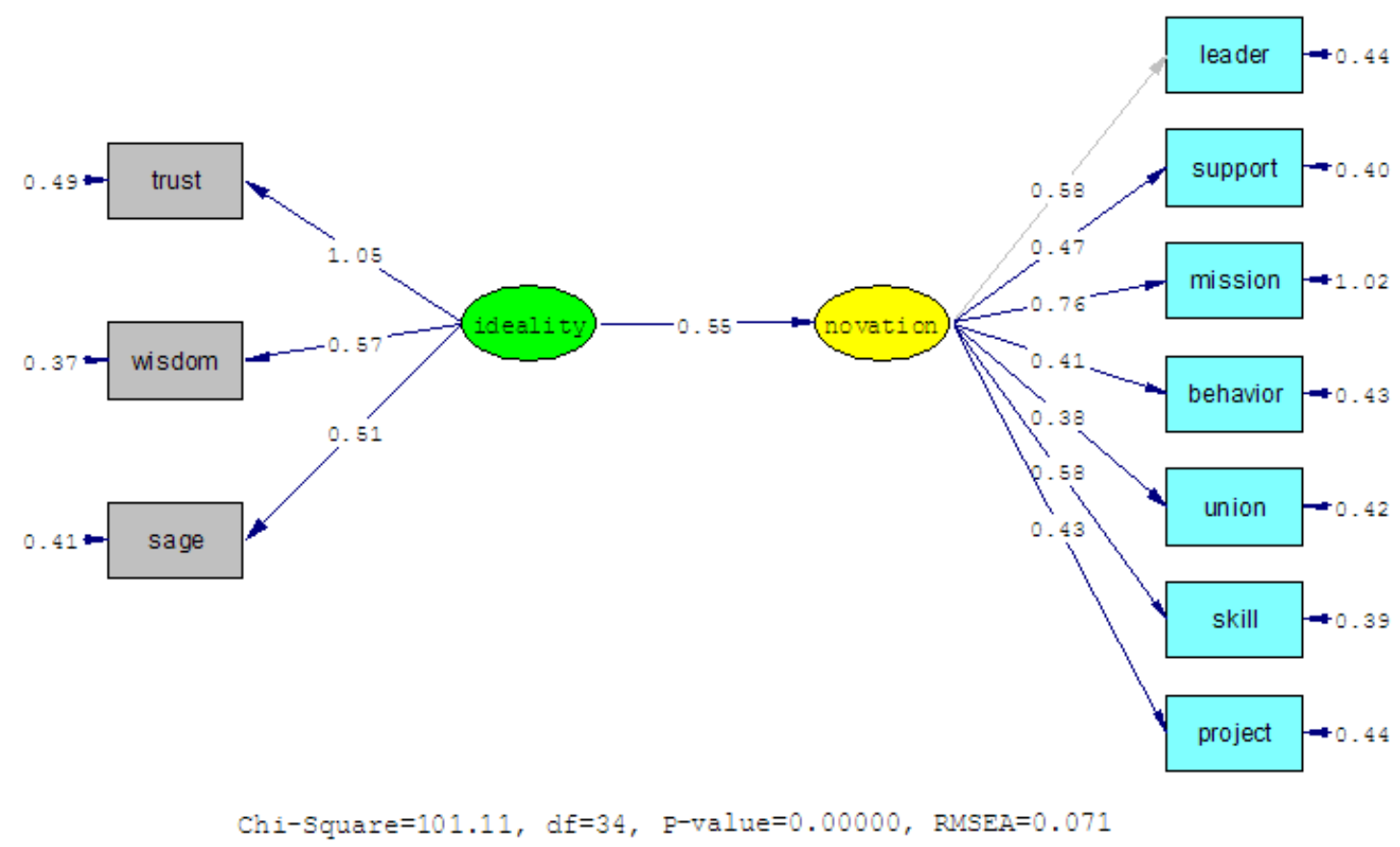

Figure 4. The structural model designed with LISREL software based on the sample under the study in a state of standard estimate

The chi-square to the degree of freedom ratio is better to be less than 3 (Human, 2012). In the above model, the number 101.11 divided by 34 results in a smaller number than 3 , which shows the model's goodness of fit ${ }^{(1)}$. Thus, the above diagram indicates the appropriate structural model affected by the parameters and variables.

\section{Fitness of the model through artificial neural network}

In the present paper, the network architecture has been only designed through using the multi-layer perceptron structure and detailed information of artificial intelligence is beyond the scope of this research. 


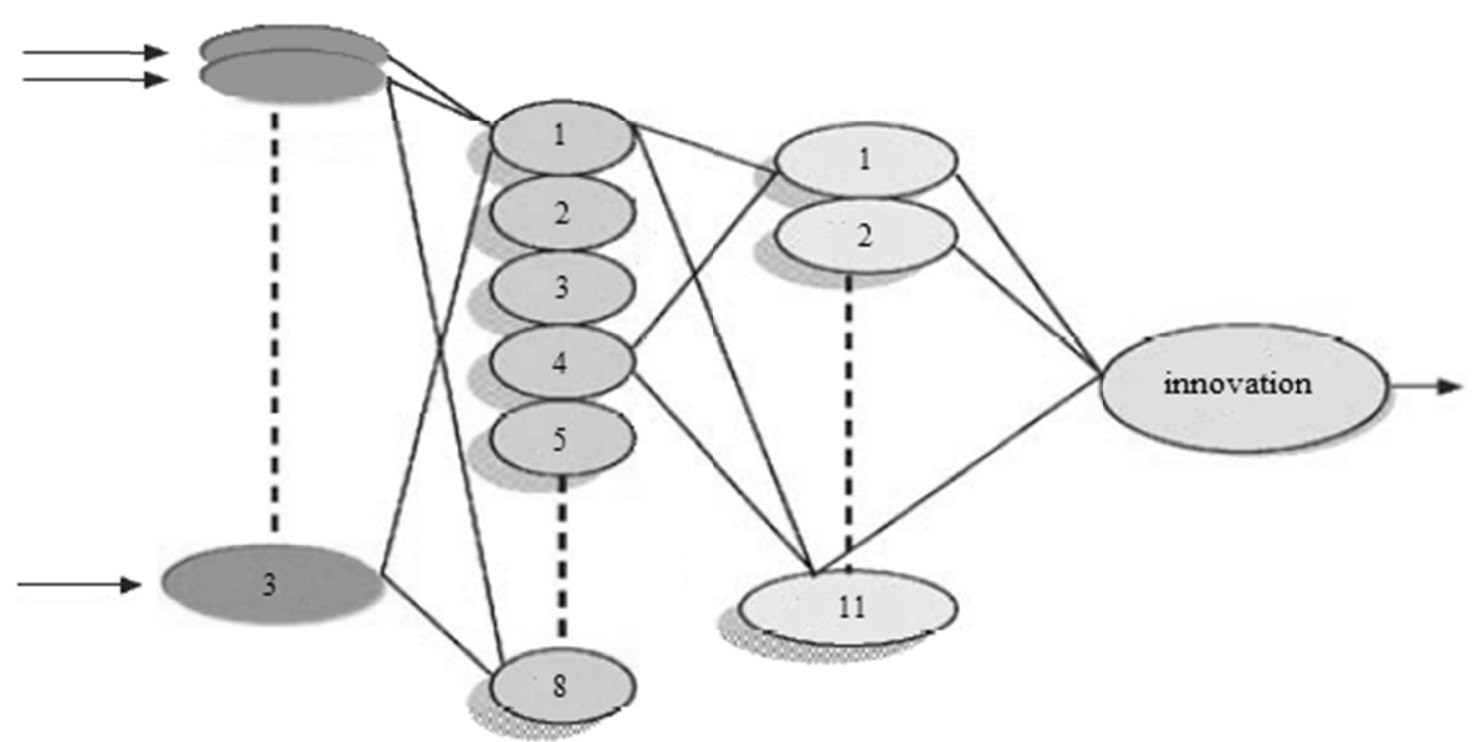

Figure 5. Network architecture, multilayer perceptron structure

Moreover, the Fisher test has been show below for equality of classical statistical correlation coefficient (SEM) and artificial intelligence (artificial neural network). The greater network model correlation coefficient indicates its greater power.

Table 2. Fisher test for equality correlation structural equation modeling and artificial neural network model

\begin{tabular}{cccc}
\hline Correlation for SEM & Correlation for ANN & D Test & Result \\
\hline 0.64323 & 0.71084 & 0.73856 & Confirmed \\
\hline
\end{tabular}

\section{Results, Future Research}

The results briefly indicate that all aspects and variables of the conceptual research model under the study have been explained in the innovation development based on Islamic spirituality variables (Islamic thought and attitude). Ways of thinking and attitude that will determine the causes of happiness and success in the society. The model has been confirmed in both classical statistics and artificial intelligence. The Fisher test for equality of structural equation modeling correlation coefficient and artificial neural network indicates the network model greater power. This study is a case study in the education system, the generalization of which to other aspects of the Islamic Republic of Iran can be helpful. The study has many limitations such as the lack of retuning of many questionnaires as well as the lack of interest and motivation by many professors and graduate students in filling out the questionnaires. The future researchers should select a majority of their participants from among influential people within the organization as they have the greatest impact on the creativity and innovation of their organizations. The current model obtained based on the conducted case study clearly reveals the innovation of Islamic human sciences. The reason is that education of people is everything in the education system. It should be noted that the innovation has a clear relation with the organization development and all dimensions and variables explained in the study including leadership, support, task or mission, behavior and interactions, coordination and integration, knowledge and skills, information and communication as well as conducting internal and external projects, reveal a form of Pure Mohammadian Islam by relying on faith in God, religious knowledge as well as wisdom and insight. This model can be considered as an initiation towards changes in an organization structure and explain an increase in the creativity and the development of innovation with Islamic orientation. In other words, we can say that the Islamic-oriented innovation creates a new structure for organizations. In accordance with the orders of the Supreme Leader, progress, creativity and innovation will be achieved when such an Islamic humanistic thinking and attitude includes all aspects of the Islamic Republic of 
Iran.

\section{Recommendations}

The recommendations of the study are as follows:

$\checkmark \quad$ conducting the study at the province or country level in a way that it geographically covers large areas

$\checkmark \quad$ conducting the study on individuals that are most effective in developing the organization innovation

$\checkmark \quad$ conducting the study on all aspects of the Islamic Republic of Iran so that the Iranian Islamic orientation is revealed in accordance with the statements of the Supreme Leader

\section{References}

Azar, A., \& Momeni, M. (2011). Statistics and its application in management (15th ed.). Tehran, Samt Publication.

Danaiee fard, H., Alvani, M., \& Azar, A. (2008). Quantitative research methodology in management, a comprehensive approach (1st ed.). Tehran, Safar-Eshraghi Publication.

Diani Dardashti, A. (2010). Quran, creativity and innovation. Bayenat Quarterly, 17(2).

Farshi, A. A. (n.d.). the lexicon of the Quran, 292.

Gheraati, M. (2013). Three hundred points in the Islamic management. the Cultural Center of Lessons from the Quran.

Human, H. A. (2012). structural equation modeling using LISREL software (5th ed.). SAMT Publication Center. Development and research organization of Textbooks for Social Sciences.

National Center for Landuse Planning - Guidelines for formulating the planning studies.

Notification of general science and technology policies (higher education system, research and technology) to the heads of the three branches and the chaiman of the Expediency Discernment Council of the System in implementing Paragraph 1 of Article 110 of the Constitution.

Pourtahmasbi, S., Tajvar, A., \& Seyyedkalan, S, M. (2010). The relationship between individual and organizational factors and creativity of high school principals in Ardebil. initiative and creativity in science, 1.

Raghib Isfahani, H.Mufradat Alfadh al-Qur'an, the reseach by Safwan Adnan Dawoodi, 296.

Rezaeian, A. (2002). creativity in the humanities. Farabi Bimonthly, 3.

Roodsaz, H., \& Bisheh, M. (2014). The role of Islamic spirituality in the occurrence of organizational citizenship behavior. Resource Management in Law Enforcement Force Quarterly, 4.

Sabzevari, M. Description of the Poem, 9. Sadeghi, M.,Sadeghi, A., Nikookar, Q. KhorshidiNaderi, A. R. (2011); "Analysis of the model of organizational, individual and group factors affecting the development of innovation in research and technology organizations", technology research and development, year three, volume 5 .

Saeida Ardakani, S., Konjkav Monfared, A. R., Hakaki, S. M., \& RezaieDolatabady, H. (2013). on the identification of factors affecting the development of individual innovation. Technology Development Management Quarterly, 2.

Sajadian, M. (2013). examining the effectiveness of establishing Geoinformatics in the Higher Education on improving the efficiency of applied research and the geographical axisiusse. University Jihad.

Sekaran, U. (2011). Research methods in management, translated by Mohammad Saebi and Mahmoud Shirazi, Tehran, Presidential Education Center of Public Administration Publication, the twelfth edition.

Steyn, Jacques. Van Belle, Jean-Paul. Villanueva Mansilla, Eduardo. (2011). "The Role of Statistics in Development Informatics" Written by Jacques Steyn. ICTs for Global Development and Sustainability: Practice and Applications, Chapter 16. Monash University, University of Cape Town, South Africa, Pontificia Universidad Catolica del Peru. Statements of the Supreme Leader among university professors and academics.

Tang, H. K. (1998). An inventory of organizational innovativeness. Retrieved from http://www.sciencedirect.com/science/article/pii/S0166497298000777

The Holy Quran, a book of guidance. 
The Holy Quran, Surah Al-Hijr, Verse 86.

The Holy Quran, Surah Yasin, Verse 81.

Valiollahpur, M. (2014). "Moving beyond the modern and regressive model of the postmodern perspective towards new ways of understanding meta-paradigmatic changes of imagination torque based on the practical models in the education and training system", International Symposium on Management Sciences, Tehran, the capital of achieving solutions for sustainable development.

Valiollahpur, M. (2015). "Presenting Innovation Model Islamic Human Sciences in Educational System Based on Statement Ayatollah Khamenei" the first conference of the Islamic Humanities, Qom, Oral Presentation, published in the Journal of the Islamic Humanities related to Iranian Social Research Association.

Valiollahpur, M. (2015). Development Innovation Model Islamic Human Sciences Based on Holy Quran and Statement Ayatollah Khamenei. Journal of New Ideas in Science and Technology, Islamic Azad University, Kerman.

Valiollahpur, M., \& Valiollahpur, S. (2014). "Studying Commercial Metropol on International Economic Policies in The Islamic Republic of Iran's Mutual Interaction Flows by Country Separation with Analytic Attitude of Geoinformatics and Geomatics", National Conference on Strategic Analysis of the Supreme Leader's views on economics and management, Islamic Azad University, Babol, Selected speech, published in the Journal of Islamic Humanities connected to Iran's Islamic Association of social science research, July 2014.

\section{Note}

Note 1. There are other indices for the model fitness. Root Mean Square Error of Approximation (RMSEA) was calculated to be less than 0.08 indicating a good fit of the model. Root Mean Square Residual (RMR) was near zero and Goodness of fit index (GFI), Adjusted Goodness of Fit Index (AGFI) and Bentler-Bonnet Fit Index and the same indices (Comparative Fit Index (CFI), Non-Normed Fit Index (NNFI), Normed Fit Index (NFI)) were calculated to be greater than 0.9 .

\section{Copyrights}

Copyright for this article is retained by the author(s), with first publication rights granted to the journal.

This is an open-access article distributed under the terms and conditions of the Creative Commons Attribution license (http://creativecommons.org/licenses/by/4.0/). 